\title{
POWER STRATEGY SCHEME OF A STANDALONE WIND ENERGY SYSTEM
}

\author{
Abdelhaq Amar Bensaber ${ }^{1}$ \\ ${ }^{1}$ University of Science and Technology of Oran - Mohamed-Boudiaf- \\ ${ }^{1}$ abs.abdelhak@gmail.com
}

\begin{abstract}
The best solution for isolated areas is to use a wind turbine associated with batteries because it is a reliable power system, however, the random nature of weather conditions and the nonlinearity of the system cause a variation in voltage, power and frequency. This paper proposes a power control strategy to attain maximum performance despite any uncertainties and coordinated by an intelligent control to deal with the power flow between the wind turbine power system and the batteries in order to satisfy the load requirements while keeping the state of charge within secure limits. The proposed standalone is tested with variable conditions to affirm the efficiency of the proposed control.
\end{abstract}

\section{Keywords-MPPT, DFIG, SOSMC, management, Battery, DC/DC converterx}

\section{INTRODUCTION}

Nowadays, the demand of sustainable and environment-friendly energy has increased rapidly to deal with issues like pollution and global warming $[1,2]$. WTs is one of the most developing renewable sources especially for the isolated area due to its high efficiency and reliability. Thus, those factors became important topics in industry and research [3-5]. However, the intermittency of wind speed can cause critical problem, to overcome this problem energy storage device is required. Yet, frequent charge and discharge decrease the battery life cycle, thus power management is necessary to prolong the battery life cycle and to suppress the power fluctuation and to supply a quality power to load[6, 7].

A very important aspect when designing a renewable distributed generator is the determination of the control strategy. Hence, this paper proposes two-layer power control scheme for a wind turbine equipped with doubly fed induction generator and a battery. First, to attain maximum performance many researchers, control schemes are proposed the vector control with the classical controller, Yet, the WECS is characterized by several uncertainties and disturbances, which may be internal or external, such as the nonlinear behavior of the WECS, the presence of DFIG parameter uncertainties, and the strong wind speed variations [8]. For this reason, it is difficult to limit these perturbations when using a linear control technique like the classical PI control. Therefore, researchers used robust control strategies for such as Sliding Mode Control, smart control or adaptive algorithms[9], HOSMC[10, 11]. In this present paper, SOSMC is suggested because it has many several features like:

- Robustness.

- perfect tracking in spite of internal and external uncertainties

- Subtraction of mechanical stresses and chattering.

Received: August 6, 2019

Reviewed: October 15, 2019

Accepted: October 19, 2019

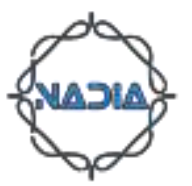


- Easy to implement.

The second layer is an implementation of a fuzzy logic controller to manage the flow of energy in a wind-battery standalone for island communities. The aim of our method is to optimize the power between the sources for various operation modes, and to preserve the SOC at a reasonable level. Finally, Simulation are carried out in matlab to verify the effectiveness of the proposed control scheme.

\section{WIND TURBINE WITH BATTERY}

In this study an intelligent management strategy in order to ensure energy of a standalone. To achieve our objective, our strategy is based on two steps is considered. The first step consists on generating the maximum power from the sources in order to generate enough energy to satisfy the load, then an intelligent controller is designed to manage the power flow from the source and play an important role in charging and discharging of the battery.

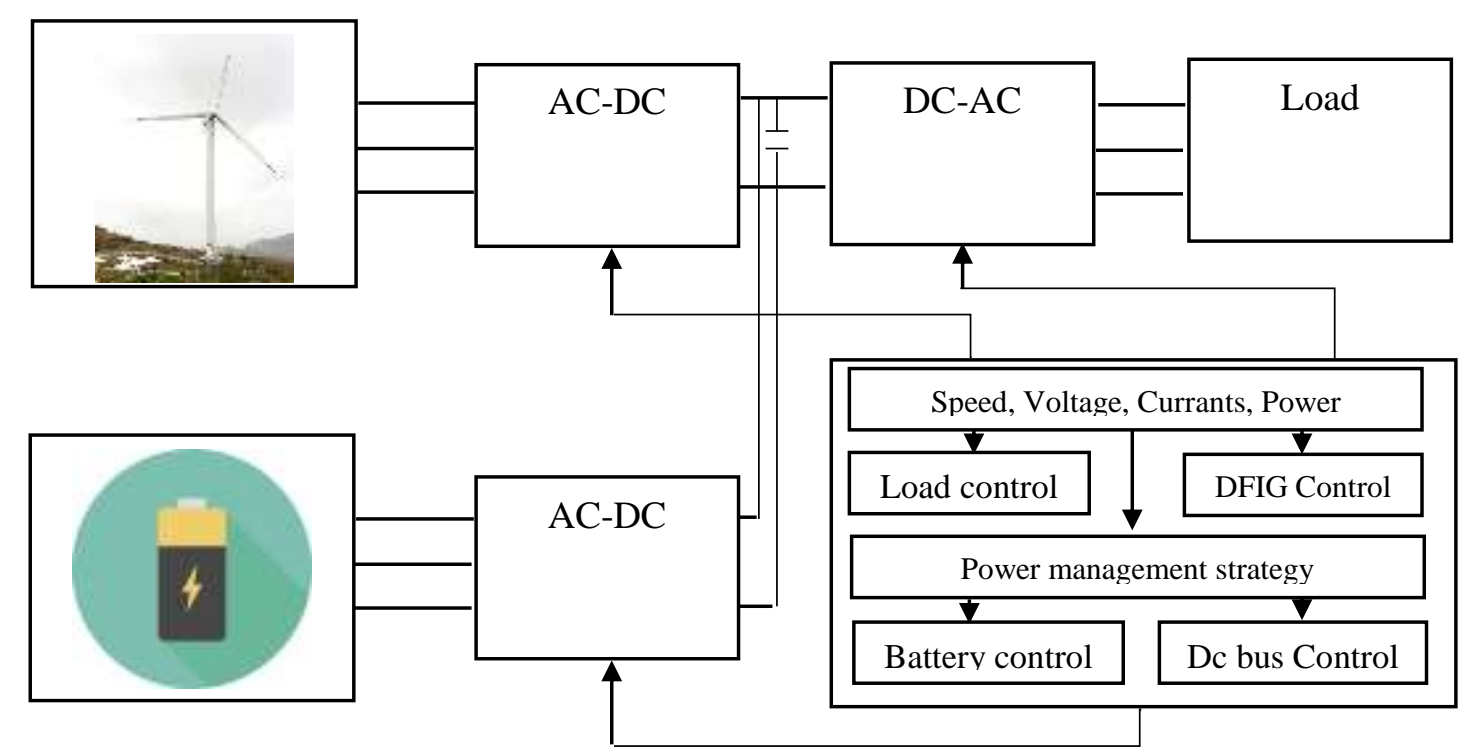

Fig. 1 Configuration of the standalone

\section{CONTROL OF WIND TURBINE}

The control system of DFIG wind turbine consists of two parts: Control of the DFIG and battery management (Fig. 1). The first control objective is to control regulate the active and reactive power independently, the second is to manage the power exchanged with the load.

\section{TURBINE MODEL:}

The energy at a speed $V v$, surface $A 1$, is expressed by[12]:

$$
P_{v}=\frac{1}{2} \rho A_{1} V_{v}^{3}
$$

but WT power is:

$$
P_{v}=\frac{1}{2} \rho \pi R^{2} V_{v}^{3} C_{p}
$$


Where: $C_{p}$ is power coefficient [13]. The speed ratio $\lambda$ introduced by:

$$
\lambda=\frac{R \Omega_{t}}{V_{v}}
$$

Where $R$ is the blade length, $\Omega_{t}$ : rotor angular speed. The slow shaft mechanical torque $C t$ is expressed by:

$$
C_{t}=\frac{P_{t}}{\Omega_{t}}=\frac{\pi}{2 \lambda} \rho R^{3} v^{2} C_{p}
$$

\section{Maximum Power Tracking MPPT}

Direct speed controller (DSC) concept is founded on generating the optimal turbine speed for various wind speed value, and use it as speed reference [14, 15]. The reference rotational speed is defined by:

$$
\Omega_{t}^{*}=\left(\lambda_{\text {opt }} v\right) / R
$$

Thus,

$$
\Omega_{m}^{*}=G \Omega_{t}^{*}
$$

We obtain the active power reference by:

$$
P_{s_{-} r e f}=C_{\text {cem_ref }} \Omega_{m}
$$

\section{MATHEMATICAL MODEL OF DFIG}

We have chosen to use the DFIG because it is possible to work in both subsynchronous and super-synchronous. The electrical model of the machine obtained using Park transformation is given by the following equations $[13,15,16]$ :

$$
\begin{aligned}
& V_{q s}=R_{s} I_{q s}+\frac{d \phi_{q s}}{d t}-\omega_{s} \phi_{d s} \\
& V_{d r}=R_{r} I_{d r}+\frac{d \phi_{d r}}{d t}-\omega \phi_{q r} \\
& V_{d s}=R_{s} I_{d s}+\frac{d \phi_{d s}}{d t}-\omega_{s} \phi_{q s} \\
& V_{q r}=R_{r} I_{q r}+\frac{d \phi_{q r}}{d t}-\omega \phi_{d r}
\end{aligned}
$$

\section{PROPOSED CONTROL}

SMC is an interesting nonlinear method approach. However, the biggest problem of this method is the chattering phenomenon which overheating and trigger unmodeled high frequency dynamics [17]. SOMC is an attractive solution [18], it generalizes the sliding mode idea by going to a higher order time derivatives, which decrease chattering and avoid powerful mechanical efforts while maintaining advantages of the SMC [17, 18], such as robustness under uncertainties. The switching functions are adopted as follow.

$$
\left\{\begin{array}{l}
S_{P}=e_{P}+c_{P} \int e_{P} d t \\
S_{Q}=e_{Q}+c_{Q} \int e_{Q} d t
\end{array}\right.
$$

The integral terms $c p$ sand $c Q$ are positive constant, are added for steady-state errors elimination $[17,19]$. The voltage applied represented in the equation below:

$$
\left\{\begin{array}{l}
V_{d r}=V_{d r e q}+V_{d r n} \\
V_{q r}=V_{q r e q}+V_{q r n}
\end{array}\right.
$$


The system in reach the sliding surface with the help of the switching control Vdrn and Vqrn ; Vqreq and Vdreq are the equivalent control terms ,they make the system move along the sliding manifold and accelerate the response of the system while reducing the steady-state errors[20]. The equivalent control terms are derived by letting $S_{P}^{\mathcal{L}}=S_{Q}^{\mathcal{L}}=0$, the voltage to be applied to the rotor are expressed as:

$$
\left\{\begin{array}{l}
V_{\text {qreq }}=-\frac{L_{s} L_{r} \sigma}{M V_{s}}\left(P_{s_{-} r e f}^{\cdot}+c_{P}\left(P_{s_{-} r e f}-P_{s}\right)\right)+R_{r} I_{q r}-g w_{s} L_{r} \sigma I_{d r}-g \frac{M V_{s}}{L_{s}} \\
V_{\text {dreq }}=-\frac{L_{s} L_{r} \sigma}{M V_{s}}\left(Q_{s_{-} r e f}+c_{P}\left(Q_{s_{-} r e f}-Q_{s}\right)\right)+R_{r} I_{d r}-g w_{s} L_{r} \sigma I_{q r}
\end{array}\right.
$$

Thus;

$$
\begin{cases}V_{d r n}=y_{1}+B_{1}\left|e_{P}\right|^{\frac{1}{2}} \operatorname{sign}\left(e_{Q}\right) & \underset{1}{\&}=B_{2} \operatorname{sign}\left(e_{Q}\right) \\ V_{q r n}=y_{2}-B_{3}\left|e_{P}\right|^{\frac{1}{2}} \operatorname{sign}\left(e_{P}\right) & y_{2}^{\&}=-B_{4} \operatorname{sign}\left(e_{P}\right)\end{cases}
$$

Where $B 1, B 2, B 3$ and $B 4$ are constants

\section{POWER MANAGEMENT STRATEGY}

The intermittent nature of renewable sources is the reason why storage systems are important in the hybrid renewable system. Batteries store the surplus power generated and uses it to supply the load if it is required [6]. Bidirectional converter is needed to charge or discharge the battery in case of overflowing or deficits of the power [1,7].

In this paper a controller for the battery charge/discharge is implemented using FLC. The FLC receives the inputs to the controller and generates a degree of membership relative to each fuzzy set in the membership function then evaluates these fuzzy set memberships and decides which rules should be fired, finally it converts these values into an output control signal. Our controller has two inputs "dP (load required power- wind generators produced), SOC" and one output-battery reference power. Depending on the input values controller generates a desired value for reference battery power, it manages the power into four operating modes:

Mode 1. If $\mathrm{dP}>0$ and SOCbat $<$ SOCmax, surplus power will be charging the battery.

Mode 2. If $\mathrm{dP}<0$ and SOCbat $>$. SOCmin. In this mode, the battery acts to compensate the shortage of demanded power to ensure the balance between generation and consumption.

Mode 3. When the Battery reaches its maximum SOCbat $>$ SOCmax, and $\mathrm{dP}>0$. In this case, the wind turbine power will be reduced to meet only the load demanded power.

Mode 4 . If $\mathrm{dP}<0$ and the battery reaches its minimum SOCbat $<$ SOCmin. In this mode, the controller will disconnect the load and the battery will be charged.

The membership functions which used for input data are shown in "Figs.2-4" and the rules to be evaluated are given in "Table1". 


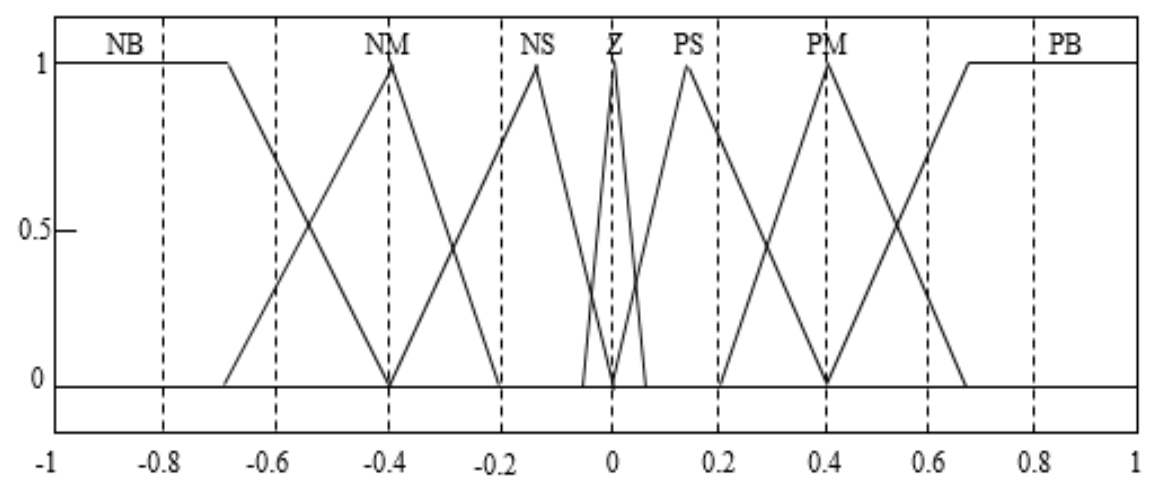

Fig. 2 Input dp.

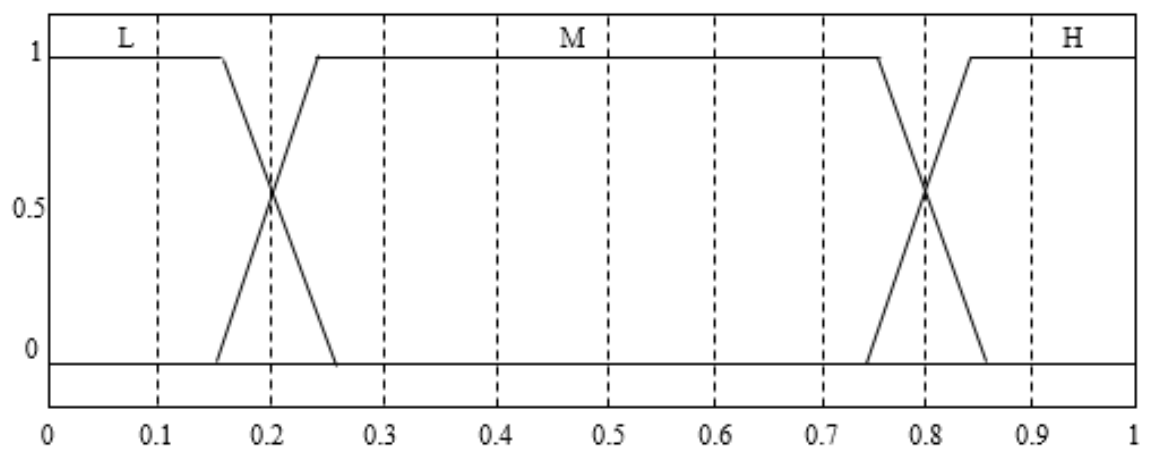

Fig. 3 Input SOC.

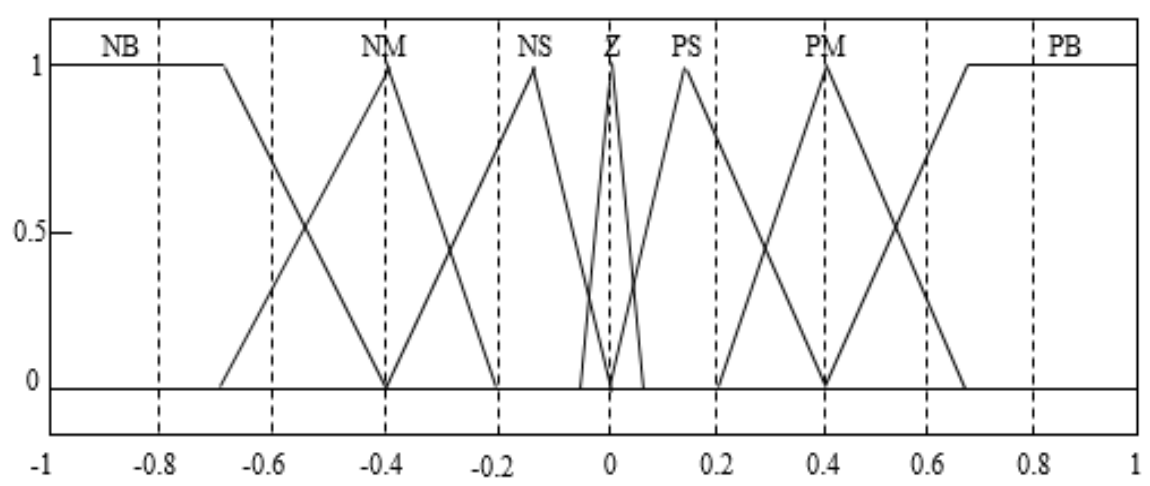

Fig. 4 Output dD.

Table1: Fuzzy logic rules

\begin{tabular}{|c|c|c|c|c|c|c|c|}
\hline SOC & PB & PM & PS & Z & NS & NM & NM \\
\hline L & NB & NM & NS & $Z$ & $Z$ & $Z$ & Z \\
\hline M & NB & NM & NS & Z & PS & PM & PB \\
\hline H & Z & Z & Z & Z & PS & PM & PB \\
\hline
\end{tabular}

\section{SIMULATION RESULTS}

Simulation are presented to verify the effectiveness of the proposed control scheme under various conditions. 


\section{A. CONTROL OF INDIVIDUAL DFIG WIND TURBINE}

Wind speed shown in Figure (5) in order evaluates the designed control.

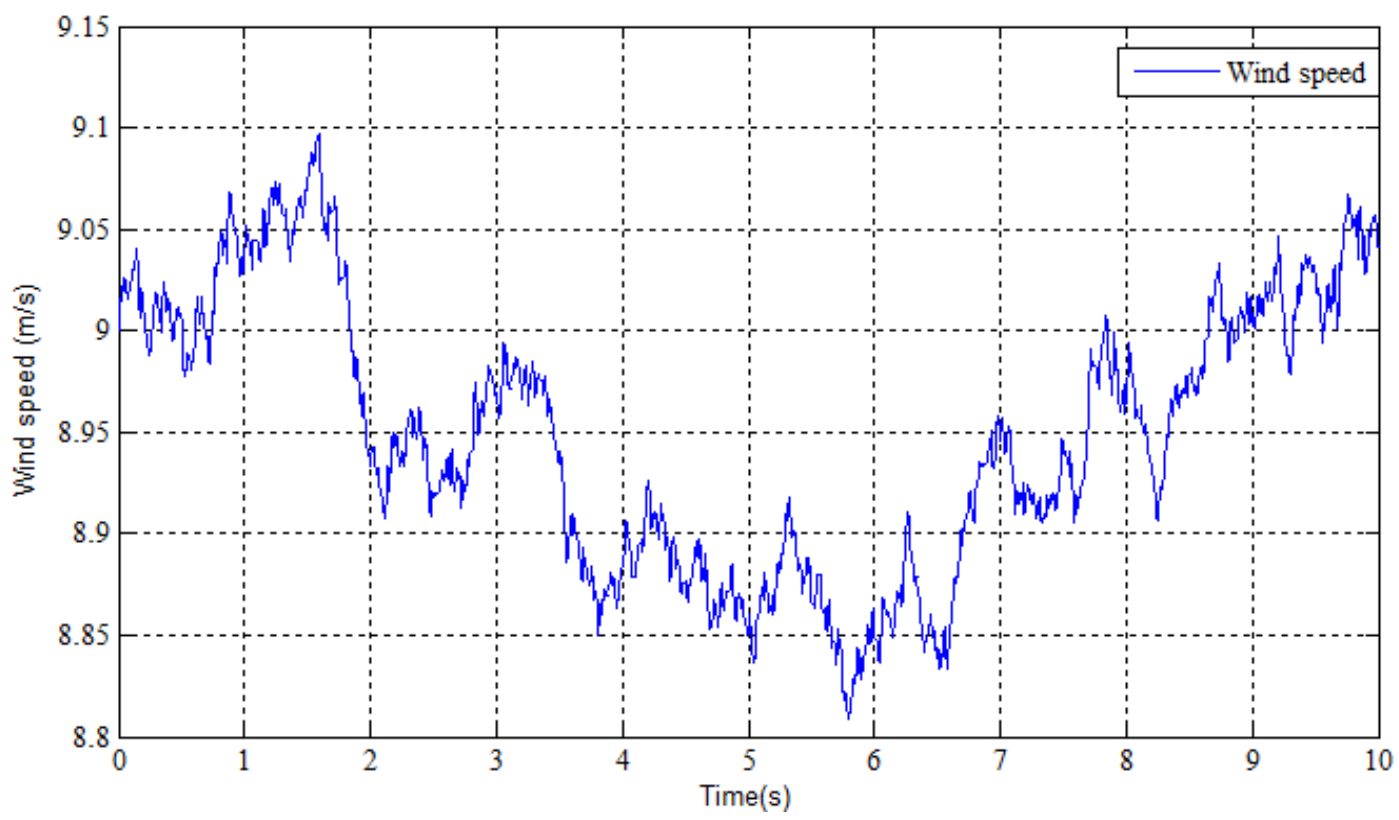

Fig. 5 Wind speed profile

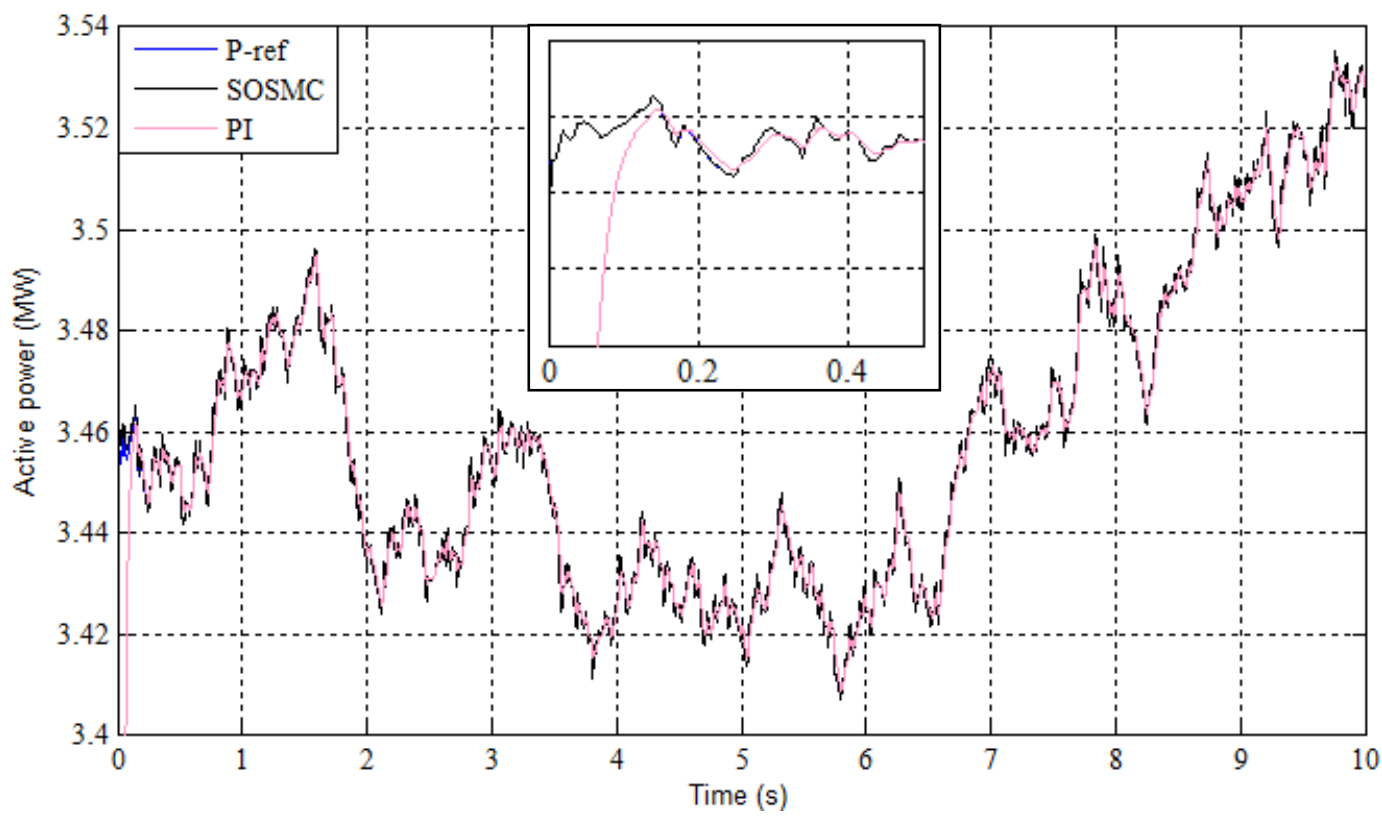

Fig. 6 Active power 


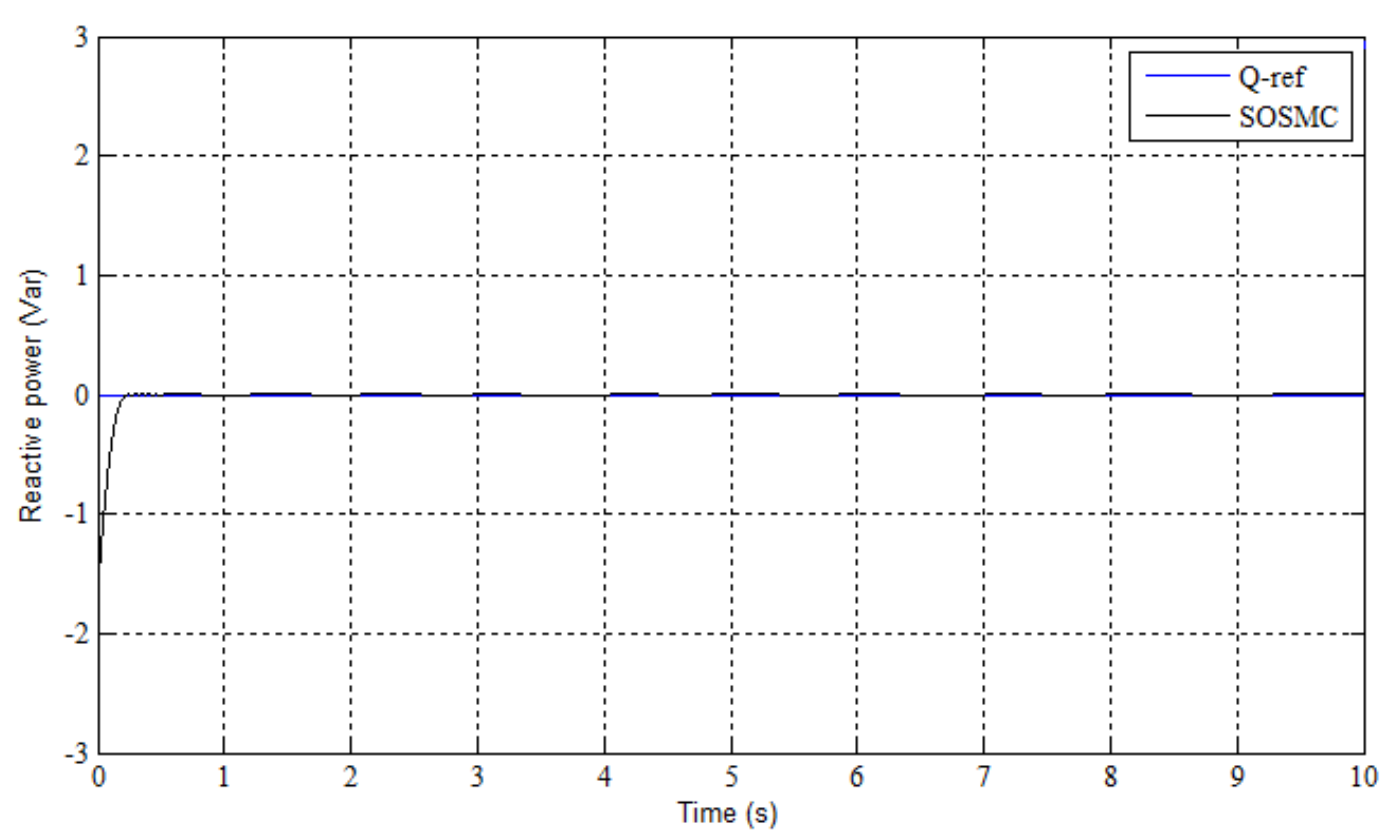

Fig. 7 Reactive power

Figures 6-7 represent the stator active and reactive powers and its reference profiles using PI and SMC, we can notice that the dynamic response under the PI control is much slower than SOSMC control while SOSMC tracks almost perfectly their references. To guarantee a unity power factor, the reactive power will be maintained zero.

\section{B. POWER MANAGEMENT STRATEGY}

In order to evaluates the designed power management a change in wind speed (figure 8) and load (figure 10) is applied.

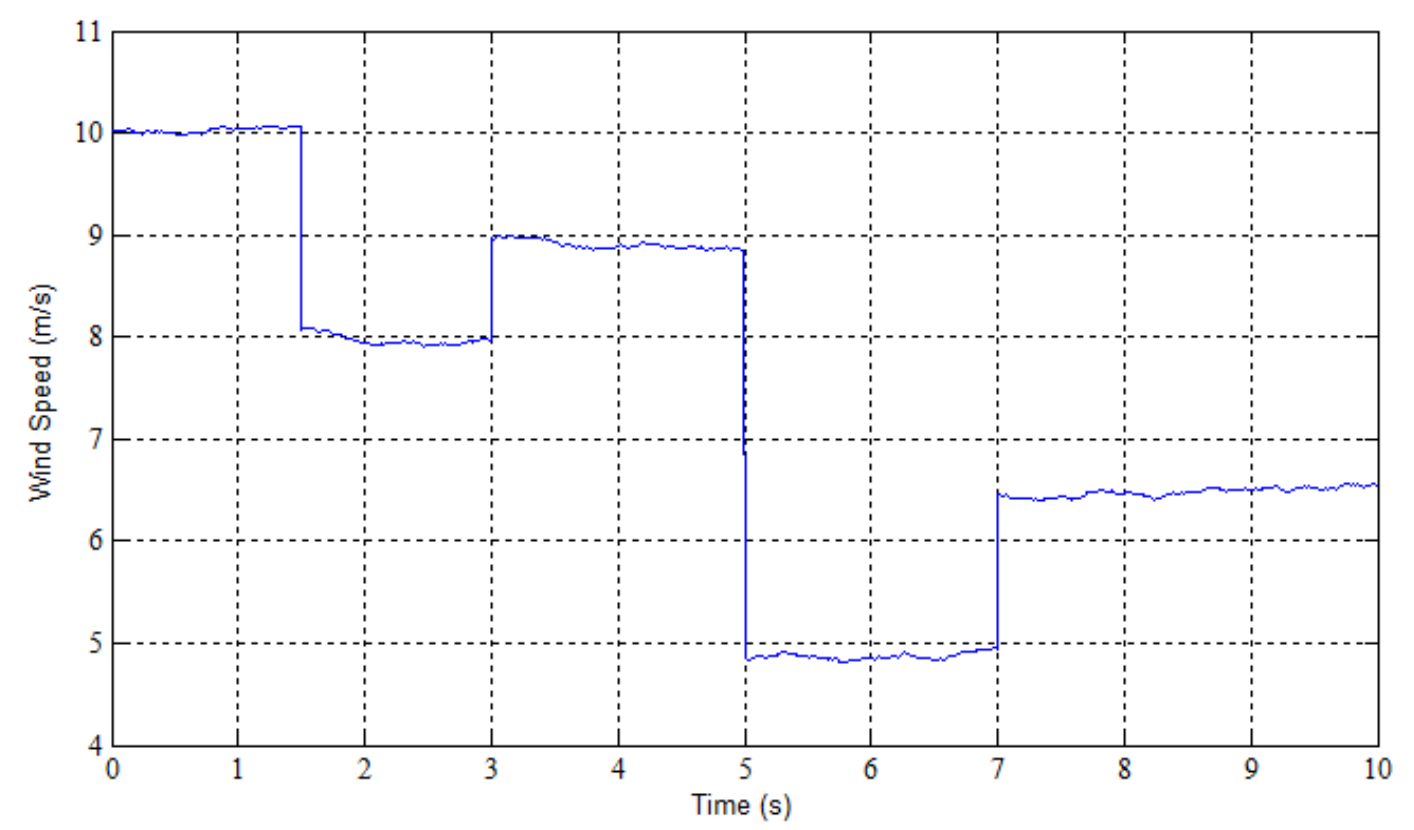

Fig. 8 Wind speed profile 


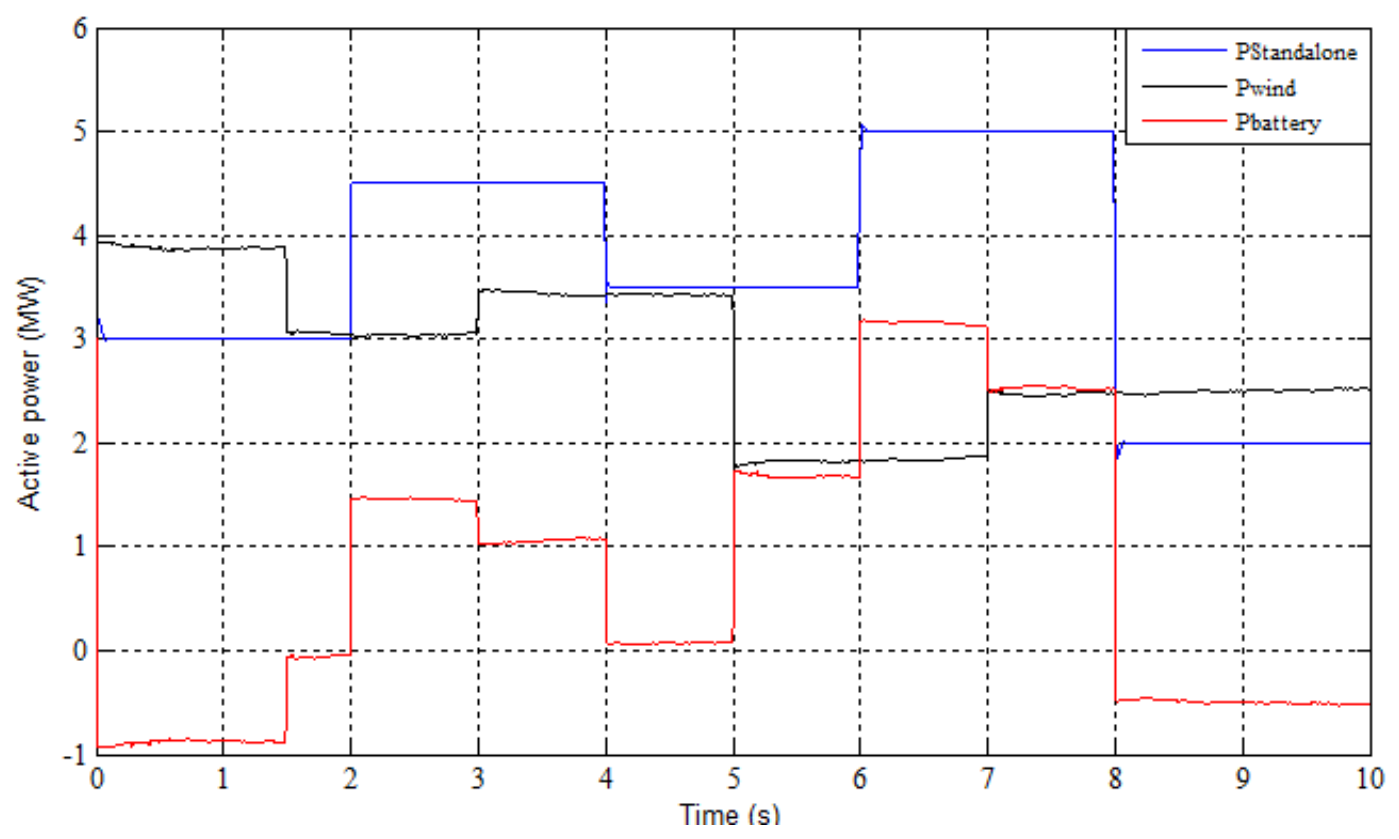

Fig. 9 Standalone power (Wind turbine and Battery power)

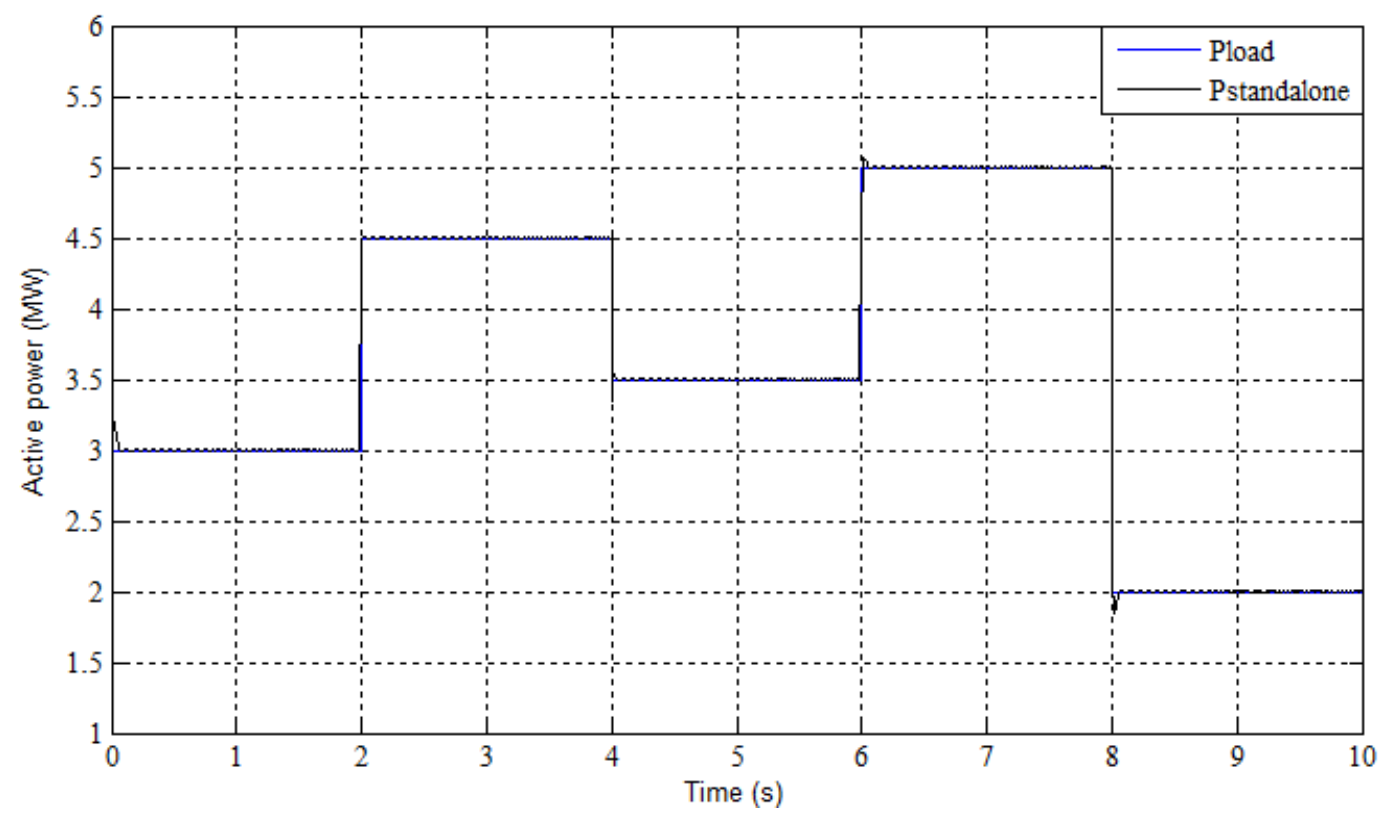

Fig. 10 Power tracking performance of standalone power during step changes in load and wind speed

The wind power is dedicated to satisfy the load demand power. In the studied system, a backup is used to maintain the balance between production and consumption at any condition (wind speed or load variation Figure 8,10). The generated active power by the standalone dynamically tracks the power demand with good precision. This power tracking capability cannot be achieved without using the battery as presented in figure 9, we can see that when the generated wind power is more than the required load power, the additional power will be transferred to the battery, but if the standalone system power can't meet the load power, the battery bank discharge and fulfill the load with the help of the DC-DC bidirectional converter. We can see that battery power vary (discharge/charge) to maintain the stability of the system as shown in Figure 9, the 
resulting output power of the standalone is therefore controlled at a constant value as required by the load. Figure 10 demonstrates that the balance between production and consumption is achieved within different production scenarios and receiver variations.

\section{CONCLUSION}

This paper presented a standalone equipped with DFIG and a battery to deal with the variations in the produced and required powers, which is connected to the dc link of the DFIG through a two-quadrant dc/dc converter. This study has three main objectives. The first one is to track the optimum power quickly despite the external or internal variations. Secondly, a fuzzy logic controller is implemented to control the power flow even under different scenarios of power generation and power consumption by the load while maintaining the battery SOC within it limits to increases it life. Results showed that the presented methods are an efficient way to control the flow of energy between input sources and storage units while ensuring a continuous power supply for the load demand even under different operation cases.

\section{REFERENCES}

[1] Amar Bensaber, A., Benghanem, M., Guerouad, A. and Amar Bensaber, M., 2019. Power flow control and management of a Hybrid Power System. Przegląd Elektrotechniczny, 95.

[2] Vigneysh, T. and N. Kumarappan, Autonomous operation and control of photovoltaic/solid oxide fuel cell/battery energy storage based microgrid using fuzzy logic controller. International journal of hydrogen energy, 2016. 41(3): p. 1877-1891.

[3] Meghni, B., D. Dib, and A.T. Azar, A second-order sliding mode and fuzzy logic control to optimal energy management in wind turbine with battery storage. Neural Computing and Applications, 2017. 28(6): p. 1417-1434.

[4] Mohammadi, A., et al., Exergy analysis of a Combined Cooling, Heating and Power system integrated with wind turbine and compressed air energy storage system. Energy conversion and management, 2017. 131: p. 69-78.

[5] Ouyang, T., A. Kusiak, and Y. He, Modeling wind-turbine power curve: A data partitioning and mining approach. Renewable Energy, 2017. 102: p. 1-8.

[6] Hemmati, R., Technical and economic analysis of home energy management system incorporating small-scale wind turbine and battery energy storage system. Journal of Cleaner Production, 2017. 159: p. 106-118.

[7] Meghni, B., et al., Effective supervisory controller to extend optimal energy management in hybrid wind turbine under energy and reliability constraints. International Journal of Dynamics and Control, 2018. 6(1): p. 369-383.

[8] Yang, B., et al., Robust sliding-mode control of wind energy conversion systems for optimal power extraction via nonlinear perturbation observers. Applied Energy, 2018. 210: p. 711-723.

[9] Abdelhaq Amar bensaber, Mustapha Benghanem, Mohammed A. bensaber, and Abdelmadjid. Guerouad "Nonlinear adaptive control for wind turbine under wind speed variation" IAES International Journal of Robotics and Automation, Vol 7, No 2: June 2018

[10] Abdelhaq Amar Bensaber, Mustapha Benghanem and Mohamed Bourahla, "Chatter-Free Nonlinear Control of DFIG Power for Wind Conversion System", International Journal of Control and Automation (IJCA), ISSN: 2005-4297(Print); 2207-6387(Online), NADIA, (2019), Vol. 12, No. 5, pp. 33-44.

[11] Sun, D., et al., A sliding-mode direct power control strategy for DFIG under both balanced and unbalanced grid conditions using extended active power. IEEE Transactions on Power Electronics, 2017. 33(2): p. 1313-1322.

[12] Lopez, J., et al., Dynamic Behavior of the Doubly Fed Induction Generator During Three-Phase Voltage Dips. IEEE Transactions on Energy Conversion, 2007. 22(3): p. 709-717.

[13] Abad, G., et al., Direct Control of the Doubly Fed Induction Machine, in Doubly Fed Induction Machine. 2011, John Wiley \& Sons, Inc. p. 363-477.

[14] Aimani, S.E., Modélisation des différentes technologies d'éoliennes intégrées dans un réseau de moyenne tension. 2004.

[15] Poitiers, F., ETUDE ET COMMANDE DE GENERATRICES ASYNCHRONES POUR L'UTILISATION DE L'ENERGIE EOLIENNE<br /> - Machine asynchrone à cage autonome<br /> Machine asynchrone à double alimentation reliée au réseau. 2003, Université de Nantes.

[16] Lie, X. and P. Cartwright, Direct active and reactive power control of DFIG for wind energy generation. IEEE Transactions on Energy Conversion, 2006. 21(3): p. 750-758. 
[17] Valenciaga, F. and P.F. Puleston, High-Order Sliding Control for a Wind Energy Conversion System Based on a Permanent Magnet Synchronous Generator. IEEE Transactions on Energy Conversion, 2008. 23(3): p. 860-867.

[18] Wen-Jieh, W. and C. Jenn-Yih, Passivity-based sliding mode position control for induction motor drives. IEEE Transactions on Energy Conversion, 2005. 20(2): p. 316-321.

[19] López, E.C. and J. Persson, High-Order Models of Doubly Fed Induction Generators, in Wind Power in Power Systems. 2012, John Wiley \& Sons, Ltd. p. 849-864.

[20] Zhu, X., S. Liu, and Y. Wang, Second-order sliding-mode control of DFIG-based wind turbines. 2014. 